\title{
Repensar la Urbanización del Litoral. El Plan Director Urbanístico del Sistema Costero de Cataluña
}

$\mathbf{R}$ : La urbanización de las áreas costeras constituye, sin duda, uno de los rasgos más característicos de la transformación del territorio en los países del sur de Europa durante las últimas décadas. La contención y ordenación de este proceso, que genera costes ambientales, urbanísticos y económicos, requiere de la adopción de nuevos instrumentos de planeamiento y gestión urbanística. El artículo analiza esta problemática a partir del ejemplo del Plan Director Urbanístico del Sistema Costero de Cataluña (PDUSC) en vigor desde el año 2005. El trabajo se divide en 4 apartados: en el primero se describe el proceso de urbanización del litoral catalán, en el segundo se expone la necesidad de disponer de instrumentos de planeamiento supramunicipal para orientar y corregir este proceso, en el tercero se detallan los objetivos y el método del PDUSC y en el cuarto se analizan cuáles han sido sus resultados tras cuatro años de vigencia. Unas conclusiones de carácter metodológico sobre la utilidad de los instrumentos de planeamiento supramunicipal en la fase actual del proceso de urbanización cierran el artículo.

Palabras-chave: Cataluña; Sistema Costero; Instrumentos de intervención urbanística.

\section{Introducción}

Una de las características más destacadas del proceso de urbanización de los países mediterráneos en las últimas décadas es la litoralización del poblamiento ${ }^{1}$. El caso español viene a confirmar claramente esta tendencia general de tal modo que, con la destacada excepción de la región metropolitana de Madrid, las mayores áreas metropolitanas - Barcelona, Bilbao, Valencia, Sevilla, Málaga - se encuentran situadas en provincias costeras. También en las costas se encuentran, por lo general, las más altas densidades de población, así como la mayor intensidad de ocupación urbana.

Este proceso de urbanización ha comportado una transformación sin precedentes del litoral español, que, con sus más de $\mathbf{8 0 0 0}$ kilómetros de longitud, se cuenta entre los más extensos y variados de Europa. La transformación, común, como decimos, a buena parta de los países del sur de Europa, ha generado indudables beneficios por lo que al crecimiento económico y a la creación de empleo se refiere. Ahora bien, por su velocidad y magnitud, la acelerada ocupación del suelo costero está poniendo asimismo en peligro parte importante de los valores ambientales, paisajísticos, urbanísticos y aún económicos que las áreas litorales - peninsulares e insulares - de España contienen. En particular, el ritmo del proceso constructivo en el período de expansión 1996-2007 ha provocado muchas voces de alarma acerca del riesgo de dilapidar de manera irreversible el patrimonio natural y los recursos de las áreas costeras, hipotecando así el bienestar de las generaciones futuras e, incluso, de la población actual.

Ante esta evolución se ha suscitado en los últimos años una intensa controversia ciudadana, disciplinar y política sobre la regulación de los usos del suelo en los espacios litorales. Uno de los elementos que con más intensidad se han ponderado en este debate es la necesidad y la utilidad de contar con nuevos instrumentos de planeamiento urbanístico y, en particular, del planeamiento supramunicipal. Como resultado de ello, los gobiernos de diversas

\footnotetext{
*Secretariø para la Planificación Territerial Generalitat de Cataluña.

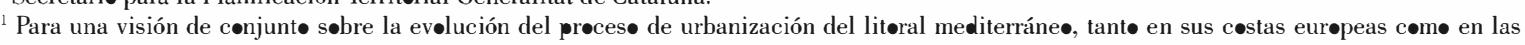
asiáticas y africanas, véase Ramøn Fol.CH y Antoni PaRIs (dir.) Atles ambiental de la Mediterrània. L'estructura del territori $i$ del paisatge, Barceløna, Institut Català de la Mediterrània - Institut Cartogràfic de Catalunya, 1999, (220 pp.)
} 
comunidades autónomas españolas han elaborado y desarrollado - con objetivos e instrumentos también diversos-planes para la ordenación de sus espacios litorales. Destacan, por su práctica coincidencia temporal, los planes específicos sobre esta materia aprobados en Murcia (2004), Cantabria (2004), Asturias (2005), Cataluña (2005) y Euskadi (2007) $)^{2}$.

La efectividad y los resultados prácticos de estos instrumentos, todos ellos muy recientes, deberán verificarse en el futuro. Se trata, sin embargo, de ejercicios novedosos que merecen la atención y el análisis disciplinar, puesto que constituyen ejemplos particularmente relevantes de las potencialidades, de las limitaciones y de la necesidad de innovación del planeamiento urbanístico supramunicipal. El presente artículo está dedicado, precisamente, al estudio del diseño y la aplicación de uno de estos ejercicios de planeamiento: el Plan Director Urbanístico del Sistema Costero de Cataluña, aprobado el año 2005. Así, en las páginas siguientes, se estudiaran, sucesivamente, el marco, los objetivos, los instrumentos y la gestión del Plan, para proponer, al final, algunas conclusiones de alcance más general sobre la utilidad del planeamiento supramunicipal para domeñar, orientar y ordenar en beneficio de la colectividad los procesos de urbanización contemporáneos.

\section{La formación de la ciudad costera: litoralización, metropolitanización y especialización turística}

El litoral catalán, como puede verse en la figura 1 , se cuenta entre las zonas más densamente pobladas de la cuenca mediterránea. Con una extensión de 670 kilómetros, su relieve a menudo abrupto y la escasez de pasos hacia el interior no han sido obstáculo para una ocupación humana milenaria, ocupación que se ha intensificado extraordinariamente en las últimas décadas debido a la presencia simultánea de tres factores: la litoralización general del poblamiento, el proceso de metropolitanización y el crecimiento de los usos turísticos.

\section{Figura 1}

Densidad demográfica en el litoral mediterráneo

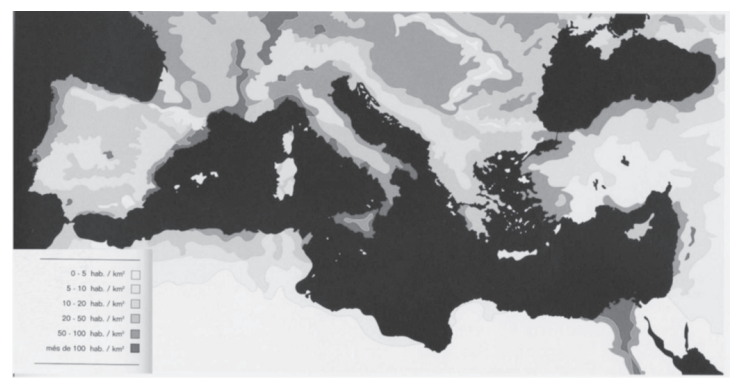

Fuente: Folch, R. y Paris, A. Atlas ambiental de la mediterrània.

La ocupación de la costa y su progresivo aumento de peso sobre el conjunto del país ha sido un proceso estrechamente imbricado con los avatares históricos de la modernización económica y social de Cataluña. Así, la litoralización del poblamiento catalán - por otra parte común a otras regiones mediterráneas ibéricas, como el País Valenciano y las Islas Baleares - tiene antecedentes que se remontan al siglo XVIII y constituye uno de los principales efectos de la industrialización, la modernización de la agricultura y la progresiva integración del espacio regional a lo largo del siglo XIX y primera mitad del xx. La atracción que la ciudad de Barcelona, principal puerto mediterráneo español, ha ejercido a lo largo de este periodo sobre el conjunto de Cataluña y otras regiones de España ha constituido uno de los principales factores que explican la intensidad y el alcance del proceso. Así, tal como puede verse en la tabla 1 , la población residente en las comarcas litorales y prelitorales pasó de representar el $68 \%$ del total de la población catalana entre 1900 y 2008.

En los últimos cincuenta años, sin embargo, la urbanización del litoral catalán se ha acelerado de

\footnotetext{
${ }^{2}$ Véase los documentos siguientes: Decreto 57/2004, de 18 de junio, por el que se aprueban las Directrices y el Plan de Ordenación Territorial del Litoral de la Región de Murcia, Boletín Oficial de la Región de Murcia, de 25 del junio de 2004; Ley 2/2004, de 27 de septiembre por la cual se aprueba el Plan de Ordenación del Litoral de Cantabria, Boletín Oficial de Cantabria de 28 de septiembre de 2004; Acuerdo de 23 de mayo de 2005, relativo a la aprobación definitiva del Plan Territorial Especial de Ordenación del Litoral Asturiano (POLA), Boletín Oficial del Principado de Asturias de 25 de agosto de 2005; Edicto del 7 de Junio de 2005 por el que se publica la resolución del Consejero de Política Territorial y Obras Públicas por la cual se aprueba definitivamente el Plan Director Urbanístico del Sistema Costero de Catalunya, Diari Oficial de la Generalitat de Catalunya de 16 de junio de 2005; Edicto de 17 de febrero de 2006 por el que se publica la resolución del Consejero de Política Territorial y Obras Públicas por la cual se aprueba definitivamente el Plan Director Urbanístico de los Ámbitos del Sistema Costero integrados por suelo urbanizable delimitado sin plan parcial aprobado, Diari Oficial de la Generalitat de Catalunya de 17 de febrero de 2006; y Decreto 43/2007, de 13 de marzo, por el que se aprueba definitivamente el Plan Territorial Sectorial de Protección y Ordenación del Litoral de la Comunidad Autónoma del País Vasco, Boletín Oficial del País Vasco de 2 de abril de 2007. Se encuentran, asimismo en trámite el Plan de Acción Territorial del Litoral de la Comunitat Valenciana y el Plan Territorial Integrado del Litoral de Galicia.
} 
forma extraordinaria, como resultado del proceso de metropolitanización, es decir, de la constitución de un área urbana integrada que, concentrando una parte substancial de la población y la actividad, ha venido a configurarse como una de las primeras metrópolis europeas ${ }^{3}$. La metropolitanización conoció una primera fase, entre finales de los años cincuenta y mediados de los setenta, caracterizada por una concentración agudísima de población y actividad en Barcelona y una treintena de municipios de su entorno inmediato, de forma que, ya en 1975, estos albergaban sobre apenas el 2,2\% de la superficie del país el 52,6\% de la población catalana. En las décadas siguientes, las dinámicas metropolitanas han experimentado un proceso de expansión, paralelo al del resto de las grandes ciudades españolas, que, por una parte, ha comportado la integración de un espacio siempre más vasto en el ámbito metropolitano, y, por otra, una notabilísima dispersión de la urbanización sobre el territorio. Así, la región metropolitana de Barcelona se extiende hoy sobre un territorio que supera los $3200 \mathrm{~km} 2$ (aproximadamente el $10 \%$ de la superficie de Cataluña) y alberga, como puede verse en la tabla 2 , cerca del $70 \%$ de la población y los lugares de trabajo. En este ámbito, Barcelona y los municipios que a ella se encuentran conurbados han tendido a perder peso relativo sobre el conjunto, mientras los territorios más alejados han crecido por encima de la media. Esto es particularmente cierto en los municipios costeros del Maresme o del Garraf, donde la urbanización se ha extendido de forma muy notable y ha venido a transformar de manera radical el tamaño y el carácter de los asentamientos preexistentes. Con las correspondientes variantes de magnitud y escala, procesos similares han tenido lugar en las áreas urbanas de Tarragona y Gerona ${ }^{4}$.

Tabla 1

El proceso de litoralización: Población del litoral Vs. Población del interior

\begin{tabular}{|c|c|c|c|c|c|c|c|c|c|c|c|c|}
\hline & 1900 & 1910 & 1920 & 1930 & 1940 & 1950 & 1960 & 1970 & 1981 & 1991 & 2001 & 2008 \\
\hline Población Litoral & 1.328 .989 & 1.426 .344 & 1.631 .789 & 2.061 .243 & 2.186 .644 & 2.490 .613 & 3.121 .326 & 4.270 .319 & 5.067 .925 & 5.219 .363 & 5.433 .808 & 6.285 .578 \\
\hline Población Interior & 637.393 & 658.524 & 712.930 & 730.049 & 704.330 & 749.700 & 767.159 & 837.287 & 888.489 & 840.131 & 909.302 & 1.078 .500 \\
\hline \multirow{2}{*}{ Total Cataluña } & 1.966 .382 & 2.084 .868 & 2.344 .719 & 2.791 .292 & 2.890 .974 & 3.240 .313 & 3.888.485 & 5.107 .606 & 5.956 .414 & 6.059 .494 & 6.343 .110 & 7.364 .078 \\
\hline & 1900 & 1910 & 1920 & 1930 & 1940 & 1950 & 1960 & 1970 & 1981 & 1991 & 2001 & 2008 \\
\hline \% Población Litoral & 68 & 68 & 70 & 74 & 76 & 77 & 80 & 84 & 85 & 86 & 86 & 85 \\
\hline \% Población Interior & 32 & 32 & 30 & 26 & 24 & 23 & 20 & 16 & 15 & 14 & 14 & 15 \\
\hline Total Cataluña & 100 & 100 & 100 & 100 & 100 & 100 & 100 & 100 & 100 & 100 & 100 & 100 \\
\hline
\end{tabular}

Fuente: Elaboración propia a partir de: Institut Català d'Estadistica.

Tabla 2

El proceso de metropolitanización:

Población metropolitana barcelonesa Vs. Resto de la población

\begin{tabular}{|c|c|c|c|c|c|c|c|c|c|c|c|c|}
\hline & \multicolumn{2}{|l|}{1960} & \multicolumn{2}{|l|}{1975} & \multicolumn{2}{|l|}{1981} & \multicolumn{2}{|l|}{1991} & \multicolumn{2}{|l|}{2001} & \multicolumn{2}{|l|}{2008} \\
\hline Total región metropo & 2.529 .495 & 65,1 & 4.019 .713 & 71,0 & 4.238 .876 & 71,2 & 4.264 .422 & 70,4 & 4.390 .390 & 69,2 & 4.928 .933 & 66,9 \\
\hline Total Cataluña & 3.888 .485 & 100,0 & 5.660 .393 & 100,0 & 5.956 .414 & 100,0 & 6.059 .494 & 100,0 & 6.343 .110 & 100,0 & 7.364 .078 & 100,0 \\
\hline
\end{tabular}

Fuente: Elaboración propia a partir de: Institut Català d'Estadística.

Tabla 3

\begin{tabular}{|c|c|c|c|c|c|c|c|c|c|c|c|c|c|}
\hline & 1995 & 1996 & 1997 & 1998 & 1999 & 2000 & 2001 & 2002 & 2003 & 2004 & 2005 & 2006 & 2007 \\
\hline $\begin{array}{l}\text { RECIOS } \\
\text { ORRIENTES }\end{array}$ & 10,3 & 10,7 & 11 & 11,3 & 11,7 & 12 & 12,1 & 11,6 & 11,4 & 10,9 & 10,9 & 10,8 & 10,7 \\
\hline
\end{tabular}

Fuente: Cuenta satélite del turismo de España. Base 2000. Instituto Nacional de Estadística

\footnotetext{
${ }^{3}$ Hemos analizado este proceso en Cataluña, ciudad de ciudades Lleida, Milenio, 2002 (160 pp). Para una comparación con el resto de las áreas metropolitanas españolas pueden verse asimismo nuestros trabajos "Las áreas metropolitanas", en A. Gil Olcina y J. Gómez Mendoza, (coord.) Geografía de España. Barcelona, Ed. Ariel. 2001 (pp. 275-289) y "¿Cambio de siglo, cambio de ciclo? Las grandes ciudades españolas en el umbral del siglo XXI", en Ciudad y territorio. Estudios territoriales, XXXVI, 141-142, otoño-invierno 2004 (pp. 523-542)

${ }^{4}$ Sobre las dinámicas territoriales en las áreas urbanas de Tarragona y Girona, con especial referencia a sus espacios litorales, pueden verse J. Oliveras y F. Gonzalez Ordenació territorial $i$ sostenibilitat al Camp de Tarragona, Tarragona, Fundació Recasens i Mercadé 2003 (225pp) y J. Nogué "La transformació del territori i del paisatge de la Costa Brava (1956-2003). Situació actual i propostes d'actuació" en III Debat Costa Brava, Colegio de Arquitectos de Cataluña, Demarcación de Girona, 2005 (pp. 88-121).
} 
Finalmente, un tercer factor ha venido a sumarse a las dinámicas de litoralización y de metropolitanización para coadyuvar de manera decisiva a la ocupación del litoral catalán: la irrupción, también a partir de la década de los sesenta, del turismo como fenómeno masivo. Esta actividad, cuya aportación al PIB a lo largo de las dos últimas décadas oscila entre el $10,3 \%$ y el $12,1 \%$ sobre el total español (Tabla 3), se ha concentrado de manera acentuada en los municipios litorales y, siguiendo el padrón común al del resto de la costa mediterránea española, se ha desarrollado en estrecha interdependencia con el sector inmobiliario. Así, el fenómeno de la segunda residencia ha ido extendiéndose de tal forma que, si en el conjunto de Cataluña ya se dedica un tercio del parque residencial a usos diversos al de la primera residencia, en algunos municipios costeros este porcentaje, de por si elevado, se supera ampliamente (como en Cadaqués, 65,8\%; l'Escala, 73,1\%; Salou, 67,4\% o Montroig del Camp, 73,7\%, para citar sólo unos pocos ejemplos). La proliferación de la segunda residencia, que predomina en la mayoría de los municipios costeros por encima de los usos hoteleros, ha acarreado un consumo muy acelerado de espacios litorales. Así, diversos estudios han mostrado como, a lo largo del último cuarto del siglo $\mathrm{xx}$, en las dos principales áreas turísticas costeras, la Costa Brava y la Costa Dorada, el consumo de suelo ha avanzado de forma acelerada ${ }^{5}$.

Como resultado de los procesos concurrentes de litoralización, metropolitanización y especialización turística, hoy cerca de las dos terceras partes de la población catalana viven en una franja de 20 kilómetros a lo largo de la costa y los 75 municipios de su litoral albergan, sobre apenas el 6,9\% de la superficie el $45 \%$ de la población. Esto comporta que casi la mitad del frente costero catalán se encuentre ya urbanizado, de modo que el caserío llega a configurar en ocasiones continuos urbanos que se extienden sin interrupción a lo largo de decenas de kilómetros de costa, como en el litoral del Maresme, el Barcelonès, el Garraf, el Baix Penedès o el Tarragonès.

\section{Figura 2}

La costa catalana cuenta con un paisaje de extraordinario interés pero ha conocido un importante proceso de urbanización. En la fotografía el Port de la Selva en el Cap de Creus

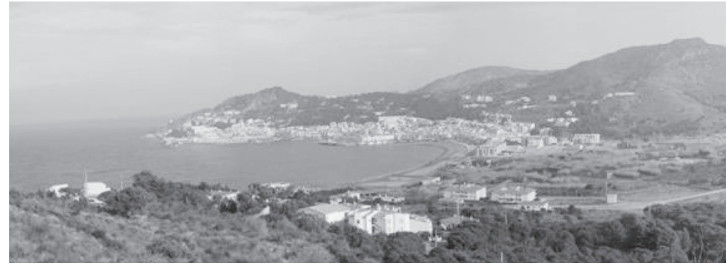

Figura 3

Ampuriabrava, construida en los años setenta, es un ejemplo de urbanización intensiva en la primera línea de costa

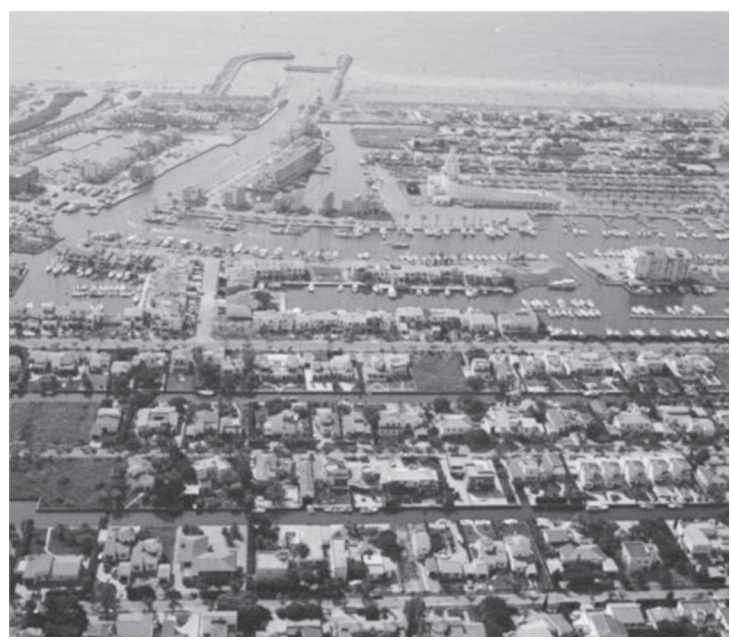

Figura 4

El Maresme, en la costra metropolitana de Barcelona, es un ejemplo de la tendencia a la conurbación de las localidades costeras y del impacto de las infraestructuras sobre el espacio litoral. En la fotografía una imagen de Arenys de Mar

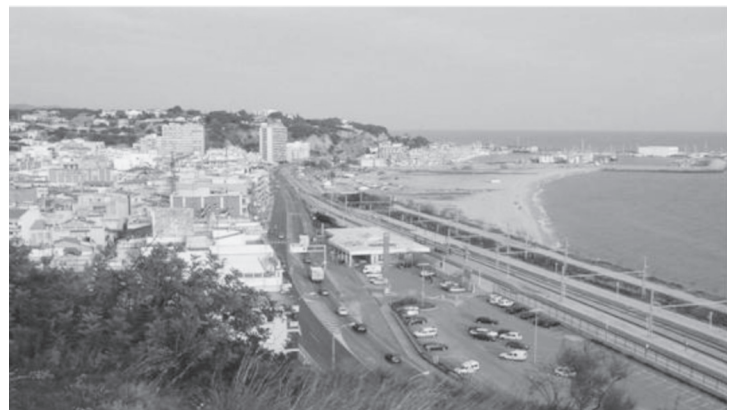

\footnotetext{
${ }^{5}$ Véase C. Martí La transformació del paisatge litoral del centre de la Costa Brava en els darrers cinquanta anys. Palamós, Calonge i Castell-Platja d'Aro, Gerona, 2001, Unidad de Geografía de la Universitat de Girona. (Memoria de investigación); H. Nuell (2001) Evolució dels usos del sòl a la Costa Brava 1957-1993 Gerona, Unidad de Geografía de la Universitat de Girona. (Memoria de investigación); J. Vicente y O. Gutierrez "La construcció d'habitatge a la provincia de Girona" en La Punxa. Collegi d'Aparelladors i Arquitectes tècnics de Girona, 36. 2004 (pp. 6-54) y también J. Oliveras y F. Gutierrez, Ordenació territorial..., cit.
} 
Los problemas que estas transformaciones suponen han sido señalados en los últimos años desde ámbitos muy diversos por instituciones académicas, colegios profesionales, entes locales, medios de comunicación, movimientos ciudadanos, e, incluso, asociaciones empresariales ${ }^{6}$. Así, con distintos matices, se ha indicado que, de perdurar las tendencias actuales en la transformación y ocupación del suelo, podrían verse comprometidas de manera irreversible la calidad ambiental, los valores paisajísticos y la eficiencia funcional del litoral catalán. Esto podría comportar graves daños para la salud del mismo sector turístico, la cual descansa, en muy buena medida, sobre el atractivo del entorno en el cual se asienta.

\section{La necesidad del planeamiento supramunicipal}

En este contexto, la decisión del Gobierno de la Generalitat de Cataluña de impulsar la elaboración de un Plan Director del Sistema Costero responde al objetivo de proteger y poner en valor el litoral catalán, ordenando el desarrollo urbanístico y evitando, siempre que sea posible, la urbanización de los espacios costeros que se encuentran todavía libres de ocupación ${ }^{7}$. La iniciativa se inscribe en el marco de una profunda renovación de los instrumentos de planificación y gestión del territorio que la administración catalana empezó a desarrollar a partir del año $2004^{8}$.

Desde la restauración de la democracia, en Cataluña se ha producido un destacado impulso del planeamiento urbanístico de escala municipal. Este florecimiento ha permitido a la práctica totalidad de los municipios catalanes dotarse de instrumentos de planeamiento general y su desarrollo en algunas ciudades - como Barcelona o Girona - ha atraído incluso la atención internacional. En cambio los avances en el campo del planeamiento supramunicipal han sido mucho más limitados y modestos.

Esta falta de instrumentos de ordenación de carácter supramunicial contrastaba con la presencia de las dinámicas de metropolitanización a las que se ha aludido más arriba. Así, problemáticas como la dispersión de la urbanización sobre el territorio, la provisión de infraestructuras para la movilidad, la protección de los espacios abiertos o la dotación de suelo para vivienda asequible, carecían de instrumentos de planeamiento territorial o urbanístico capaces de darles respuesta a la escala adecuada. Ante esta situación, el año 2004 el Gobierno de la Generalitat decidió crear el Programa de Planeamiento Territorial con el objetivo explícito de orientar y ordenar el proceso de urbanización. Este mismo año se definieron unos criterios de planeamiento territorial, en los que se adoptaba como guía la voluntad de impulsar la compacidad, la complejidad y el carácter integrado de los asentamientos, afirmando que la aplicación de estos principios constituía la principal garantía para hacer compatible el proceso de urbanización con la funcionalidad de las redes de comunicación, la eficiencia en la prestación de los servicios, el incremento de la cohesión social, la eficiencia económica a largo plazo, la preservación del paisaje y la correcta gestión de los recursos ambientales ${ }^{9}$.

Desde entonces, el planeamiento territorial ha avanzado rápidamente de forma que en la actualidad, el $73 \%$ del territorio catalán dispone ya de planificación territorial vigente a esta escala. El lector interesado en la metodología, el contenido y la aplicación de estos planes encontrará cumplida información en el artículo de Juli Esteban publicado en las páginas de esta misma revista ${ }^{10}$.

Ahora bien, este esfuerzo de planeamiento a escala territorial requería, a criterio de la administración catalana, de un mayor nivel de concreción en algunos ámbitos, en particular las áreas urbanas más complejas, los territorios con mayor dinamismo urbanístico o los espacios que atesoran valores ambientales o patrimoniales especiales. Por ello, en estas áreas se han creado instrumentos intermedios entre el planeamiento territorial y el municipal que permitan dar un marco de referencia y de coordinación a los planeamientos de los municipios que los integran: los Planes Directores Urbanísticos ${ }^{11}$.

Así, desde el año 2004, el Departamento de Política Territorial i Obras Públicas ha impulsado la redacción de un total de 35 planes directores urbanísticos, que alcanzan más de la mitad de los 946

\footnotetext{
${ }^{6}$ Diversos Autores, Debat Costa Brava, Congrés: Un futur sostenible, Colegio de Arquitectos de Cataluña, Demarcación de Girona. 2005 (p. 402 )

7 La administración autónoma de Cataluña, la Generalitat, dispone, de acuerdo con su Estatuto de Autonomía, de competencias exclusivas en materia de urbanismo y ordenación del territorio. Sin embargo, la ordenación del dominio público marítimo terrestre, es decir, del espacio de los primeros 100 m. desde la ribera interior del mar corresponde a la Administración General del Estado.

${ }^{8}$ Para una panoràmica de la política territorial catalana en los últimos años, puede verse Oriol Nel·lo (2005) "La Nuova Politica Territoriale della Catalogna" en Archivio di Studi Urbani e Regionali, 83, (pp. 39-70).

Para el caso específico de la ordenación de las zonas costeras, véase asimismo nuestro trabajo "La renovación del planeamiento urbanístico suparmunicipal. El Plan Director Urbanístico del Sistema Costero de Cataluña” en Luis Galiana y Julio Vinuesa, Teoría y práctica para una ordenación racional del territorio, (en prensa), que constituye una versión más extensa del presente artículo.

${ }^{9}$ Secretaria per a la Planificació Territorial, Planejament territorial. Criteris. Departament de Política Territorial i Obres Públiques. 2006 (p. 28 )

${ }^{10}$ Juli Esteban (2009): "El Planejament Territorial a Catalunya, avui”, en Tria. Rivista internazionale di cultura urbanistica, 3, junio 2009 (pp. $153-167$ )

${ }^{11}$ Véase el número especial de la revista Espais (núm. 52, otoño 2006), dedicada a estos planes.
} 
municipios catalanes y cubren más de un tercio de la superficie del país. Diecinueve de estos planes, entre los que se cuentan los dos Planes Directores Urbanísticos del Sistema Costero, se encuentran ya definitivamente aprobados y el resto se halla en diversas fases de elaboración y tramitación [Figura 5]. Se trata de planes que tratan de responder a problemas muy diversos y atañen, por lo tanto, a espacios muy variados: áreas urbanas medianas, territorios con especiales valores patrimoniales o paisajísticos, comarcas de montaña, áreas residenciales estratégicas, corredores de infraestructuras y, como se detallará a continuación, el sistema costero. Ahora bien, la unidad de los principios que los inspiran, la coordinación entre los equipos que los elaboran y la coincidencia temporal en su redacción les confieren una cierta identidad de carácter generacional. En las conclusiones del capítulo volveremos sobre esta cuestión ${ }^{12}$.

\section{Figura 5}

Planes Directores urbanísticos.

Estado de tramitación, septiembre 2009

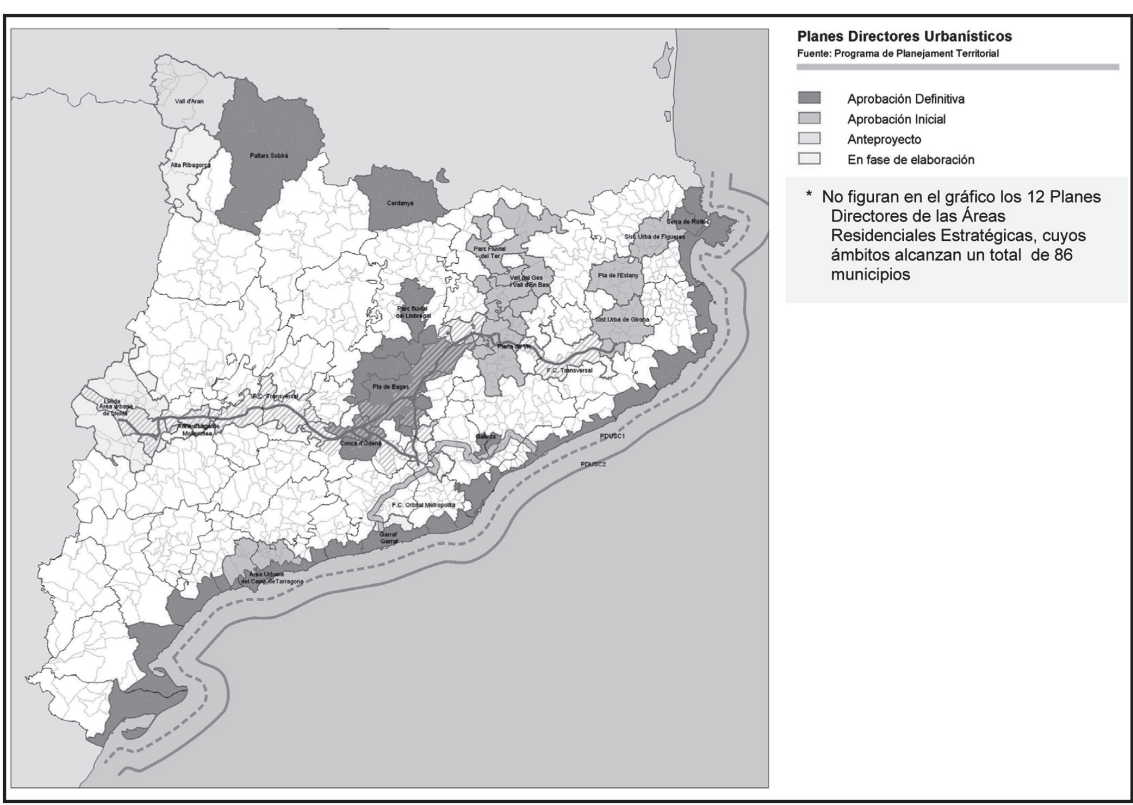

Fuente: Programa de Planificación Territorial, 2009. Generalitat de Catalunya
Para acabar con esta breve panorámica sobre la política territorial en la que el Plan Director del Sistema Costero Catalán se insiere, hay que señalar que las iniciativas en el campo del planeamiento que acabamos de reseñar han sido acompañadas, en el último quinquenio, por una transformación sustantiva de los instrumentos legislativos con los que la administración y la sociedad catalana contaban para gestionar el territorio. Así, con el objetivo explícito de adaptar el marco normativo a las nuevas realidades territoriales y a los objetivos políticos más arriba señalados, la Generalitat ha aprobado leyes en cinco campos diversos: el urbanismo, la rehabilitación urbana, las infraestructuras, el paisaje y la información geográfica. Con ello, la panoplia de instrumentos de los que se dispone para orientar, ordenar y, si es preciso, corregir el proceso de urbanización ha conocido una renovación completa.

\section{Los objetivos y el método del Plan Director Urbanístico del Sistema Costero}

Es en este contexto de renovación normativa y de impulso del planeamiento supramunicipal que se ha producido la aprobación y aplicación del Plan Director Urbanístico del Sistema Costero catalán (en adelante, PDUSC) $)^{13}$. Como se ha dicho, la iniciativa tiene como principal objetivo, preservar de la urbanización la mayor parte de los espacios costeros que se encuentran todavía libres de ocupación, dotándolos de protección a través de un documento urbanístico de carácter vinculante para el planeamiento municipal.

\footnotetext{
${ }^{12}$ Véase O. Nel·lo, "Els plans directors urbanístics de Catalunya. Una nova generació de plans", en Espais, 52, Otoño 2006. Departament de Política Territorial o Obres Públiques (pp. 3-11)

${ }^{13}$ La documentación completa del PDUSC puede consultarse en la web del Departamento de Politica Terrtitorial y Obras Públicas de la Generalitat de Cataluña (http://www10.gencat.cat/ptop/). Existe asimismo una versión publicada en volumen que incluye la memoria, la normativa, el catálogo de los espacios protegidos y la cartografía del Plan precedidos por sendos textos introductivos del Consejero de Política Territorial, Joaquim Nadal, y de los directores del plan: Oriol Nel·lo y Joan Llort (dir.), Pla Director Urbanístic del Sistema Costaner, Barcelona, Generalitat de Catalunya, 2006 (383 p.). El PDUSC ha sido objeto de diversas glosas y estudios, entre los que pueden citarse los siguientes: para una visión de conjunto, Pilar Riera y Carlos Haas, "Los planes directores del litoral de Cataluña”, en Joan Romero y Joaquim Farinós, Gobernanza territorial en España, Valencia, Universitat de València, 2006 (pp. 47-60); para un pormenorizado análisis jurídico, Josep Maria Aguirre, L'ordenació del litoral catalá: els plans directors urbanístics del sistema costaner, Barcelona, Atelier (217 p.); sobre los avatares de su tramitación y aprobación, "El Pla Director del Sistema Costaner" en Anuari Territorial de Catalunya, Barcelona, Societat Catalana d'Ordenació del Territori, 2004-2006; sobre su despliegue y gestión, Isabella Longo, El planeamiento de la costa: el caso catalán, Venecia, Istituto Universitario di Architettura di Venezia, 2007 (89 pp. tesis de licenciatura).
} 
Veamos a continuación cuales son el ámbito de aplicación, las finalidades, el método y los instrumentos del Plan.

\section{Ámbito y finalidades}

La voluntad de limitar el proceso de ocupación del litoral catalán respondía, según la Memoria del Plan, a finalidades de cuatro tipos ${ }^{14}$ :

a) Urbanísticas: evitar la consolidación de continuos edificados que podrían llegar a ocupar una parte substancial de la línea de costa.

b) Patrimoniales: proteger y potenciar los valores paisajísticos, culturales y simbólicos de los espacios costeros.

c) Ambientales: preservar un medio particularmente frágil como el costero y asegurar la continuidad entre los ecosistemas terrestres y marítimos.

d) Económicas: gestionar el espacio litoral como un recurso esencial para el desarrollo económico en general y, en particular, para la actividad turística.

Para alcanzar este objetivo, el Gobierno procedió, en el mismo momento de iniciar la tramitación del Plan (febrero 2004), a delimitar un ámbito de 500 metros a partir de la ribera interior del mar sobre la totalidad del frente costero catalán. Así, el PDUSC vino a afectar, total o parcialmente, el término municipal de 75 municipios de Cataluña [Figura 6].

\section{Figura 6}

Ámbito territorial del Plan Director Urbanístico del Sistema Costero Catalán.

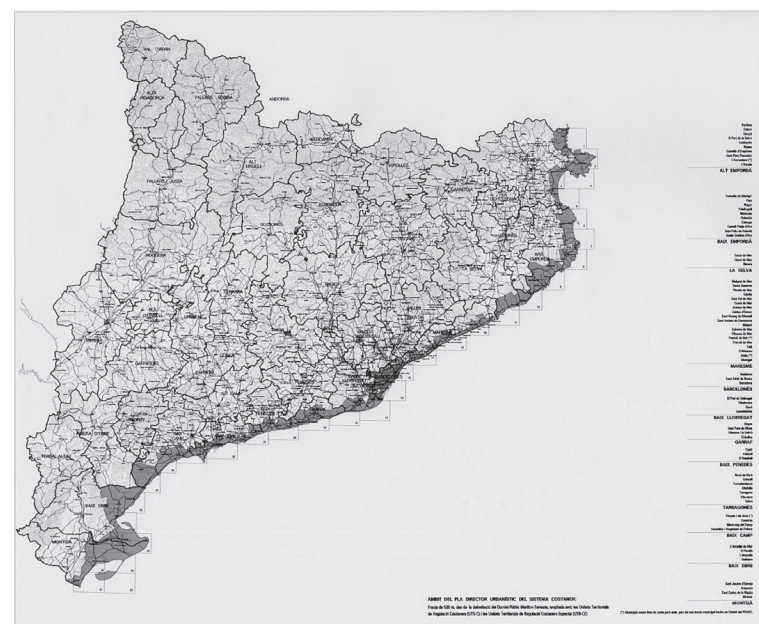

Fuente: Dirección General de Urbanismo. Generalitat de Catalunya
Como se ha indicado más arriba, se trata de un espacio ya intensamente urbanizado, de modo que, en el momento de iniciar la tramitación del PDUSC, el 46,5\% de la fachada marítima de Cataluña estaba ya clasificada como urbana. Bien es verdad que otro $39,6 \%$ gozaba de alguna forma de protección, pero esta cifra resulta, hasta cierto punto, engañosa, puesto que en esta categoría figuran los dos principales accidentes geográficos del litoral catalán, el Cap de Creus y el Delta del Ebro, la orografía tortuosa de los cuales cubre muchos kilómetros de litoral. Finalmente, el 5,7\% del suelo era considerado urbanizable en alguna de sus diversas acepciones (no delimitado, delimitado sin planeamiento parcial aprobado y delimitado con planeamiento parcial aprobado) y el $8,2 \%$ restante era suelo no urbanizable ordinario, de forma que estaba a disposición del planeamiento municipal para convertirlo, si así lo estimaba necesario y posible, en suelo urbanizable.

Pues bien, el PDUSC ha establecido que, dentro de una franja cuya profundidad oscila entre 500 y 2000 m de la línea de costa, la práctica totalidad de los suelos no urbanizables, de los suelos urbanizables no delimitados y, como se verá, de algunos suelos urbanizables delimitados deben quedar definitivamente excluidos del proceso urbanizador. Se persigue así asegurar la conectividad entre los espacios ya protegidos (como entre el espacio de interés natural de l'Albera y el Cap de Creus [Figura 7]), evitar la conurbación de los núcleos urbanos (como en el Maresme [Figura 8]), abrir los espacios protegidos del interior hacia el mar (como en Tivissa y Vandellòs [Figura 9]), o garantizar la no urbanización de las desembocaduras fluviales (como en el Delta de la Tordera [Figura 10]).

\section{Figura 7}

Ordenación del PDUSC, ámbito de las Alberas y el Cap de Creus

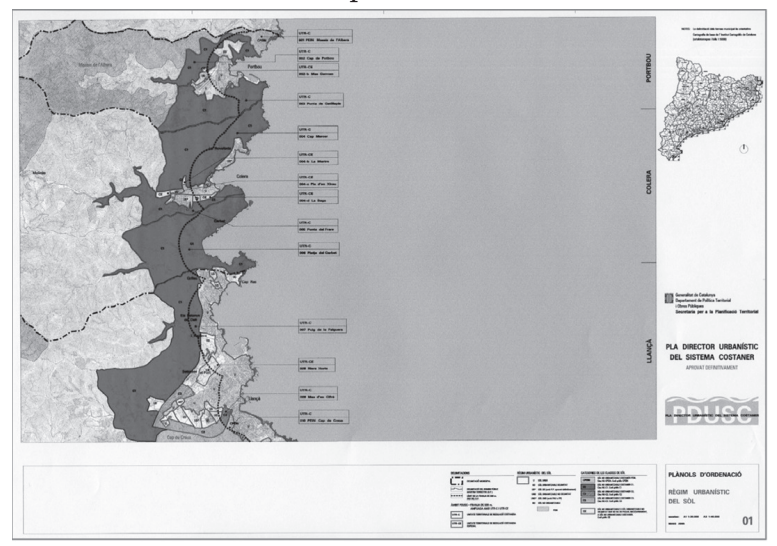

Fuente: Dirección General de Urbanismo. Generalitat de Catalunya

\footnotetext{
${ }^{14}$ Seguiremos parcialmente en el presente apartado y el siguiente, nuestro "El Pla Director Urbanístic del Sistema Costaner: una aposta de futur", en Oriol Nel-lo y Joan Llort (dir.), Pla Director...cit. (pp. 9-12)
} 


\section{Figura 8}

Ordenación del PDUSC, ámbito del Maresme

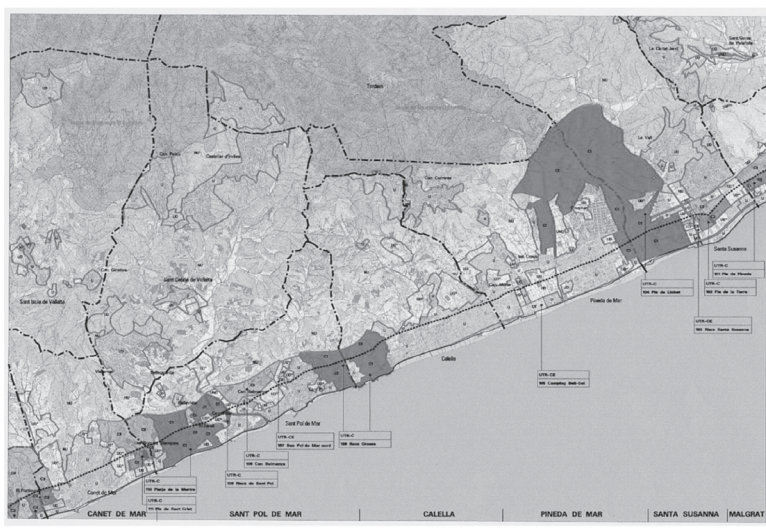

Fuente: Dirección General de Urbanismo. Generalitat de Catalunya

\section{Figura 9}

Ordenación del PDUSC, ámbito de las Montañas de Tivissa y Vandellòs

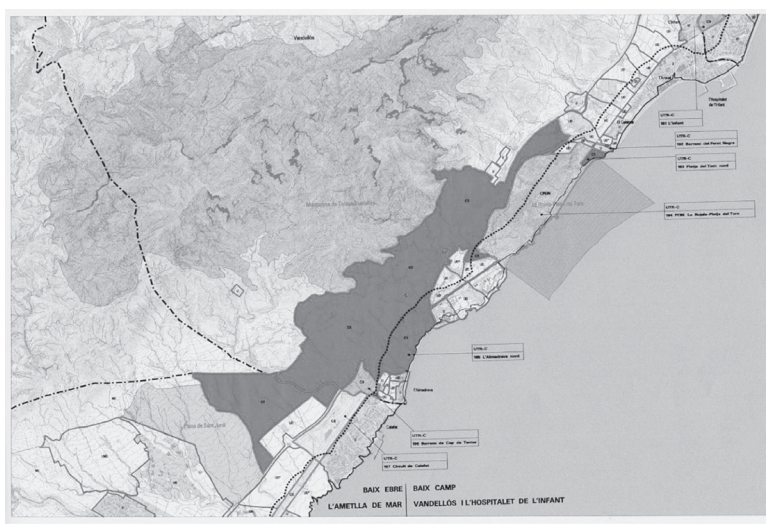

Fuente: Dirección General de Urbanismo. Generalitat de Catalunya

Figura 10

Ordenación del PDUSC, ámbito del Delta de La Tordera

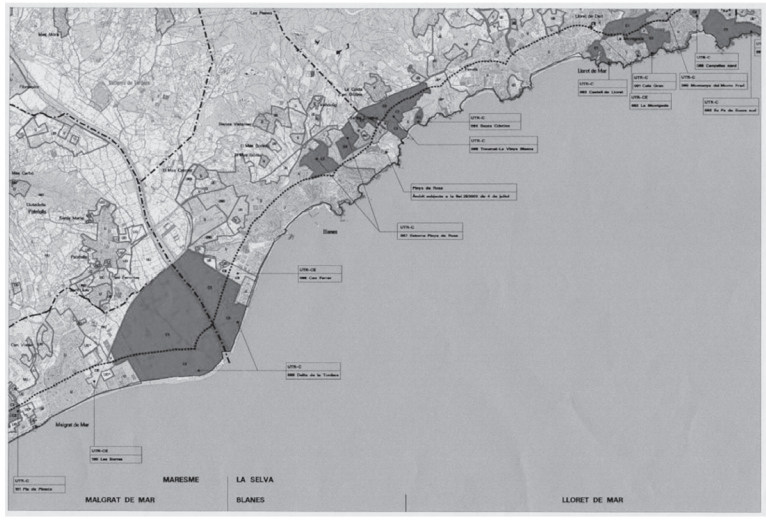

Fuente: Dirección General de Urbanismo. Generalitat de Catalunya

\section{Método e instrumentos}

Desde el punto de vista del método de planeamiento, la efectividad del PDUSC opera desde el principio de jerarquía normativa, y, en consecuencia, comporta la obligatoriedad de adaptar y/o revisar el planeamiento urbanístico municipal para adecuarlo al Plan Director. De esta forma, las disposiciones del plan constituyen directrices para el planeamiento urbanístico municipal, así como medidas efectivas de protección y gestión del suelo no urbanizable.

El procedimiento utilizado en el PDUSC es bien simple. Parte de las categorías de suelo existentes según el planeamiento municipal vigente y, para cada una de ellas, establece las previsiones siguientes:

a) Suelo no urbanizable que ya se encuentra bajo la protección del Plan de Espacios de Interés Natural. Mantiene esta condición ${ }^{15}$.

b) Suelo no urbanizable ordinario. Pasa a ser considerado en su práctica totalidad como suelo no urbanizable costero y se establece la incompatibilidad de su eventual transformación en suelo urbanizable.

c) Suelo urbanizable no delimitado. En la mayor parte de los casos, pasa a ser considerado suelo no urbanizable costero, con un tratamiento idéntico al indicado en el apartado anterior.

d) Suelo urbanizable delimitado. En esta categoría de suelo se distinguen dos supuestos. En primer lugar, se consideran los suelos que disponen ya de planeamiento parcial definitivamente aprobado, el cual podrá ser ejecutado de acuerdo con las determinaciones establecidas. En cambio, los suelos que no disponen de esta figura han sido objeto de un estudio pormenorizado que, como se expondrá a continuación, ha determinado si era conveniente o no su desarrollo, y, en algunos casos, ha establecido directrices para su ordenación.

e) Suelo urbano. Mantiene esta calificación tanto si se trata de suelo urbano consolidado como no consolidado.

\footnotetext{
${ }^{15}$ El Plan de Espacios de Interés Natural de Cataluña, aprobado el año 1992, agrupa un total de 145 ámbitos distribuidos en el conjunto del territorio catalán. En algunos casos - como en los del Cap de Creus o el Delta del Ebro, mencionados más arriba - estos ámbitos gozan además de la consideración de parque natural.
} 
Como se puede observar, la determinación esencial del Plan es incluir dentro de la definición de "suelo no urbanizable costero" una parte substancial del suelo no urbanizable ordinario y del suelo urbanizable (en especial, el no delimitado). Por lo general, los suelos incluidos bajo esta nueva rúbrica no podrán ser urbanizados, de modo que, si en la actualidad están clasificados como no urbanizables ordinarios el planeamiento municipal no podrá alterar su régimen y si están clasificados como urbanizables deberán revertirse a su primitiva condición de suelo no urbanizable.

Mención aparte merece el tratamiento que reciben los suelos clasificados como suelo urbanizable delimitado que no disponen todavía de planeamiento parcial definitivamente aprobado. Como se ha dicho, el objetivo primigenio del plan era actuar sobre suelos no urbanizables y suelos urbanizables no delimitados. Sin embargo, a lo largo del proceso de elaboración del documento se hizo evidente la importancia estratégica de preservar algunos sectores ya delimitados. Así, se decidió emprender la redacción de un nuevo Plan - denominado Plan Director de los ámbitos del Sistema Costero integrados por sectores de suelo urbanizable delimitado sin planeamiento parcial definitivamente aprobado (PDUSC-2) - que, por razones técnicas y jurídicas, se prefirió tramitar separadamente del primer PDUSC. Para la elaboración de este segundo instrumento, se procedió al estudio detallado de más de dos centenares de sectores, y se decidió establecer, finalmente, la protección de 44 de ellos por razón de sus valores intrínsecos, su proximidad a la línea de costa y la coherencia con los objetivos generales del Plan. Para 28 de estos sectores se dispuso de la necesidad de proceder a su desclasificación total, en el caso de otros 2 su desclasificación parcial y en los restantes 14 la adopción de unas directrices urbanísticas compatibles con la calidad paisajística y ambiental ${ }^{16}$. El resto de los sectores podrían completar su desarrollo urbanístico, aún cuando el Plan establece diversas condiciones al respecto, como la obligación de llevar a cabo estudios paisajísticos que garanticen la correcta integración en el entorno de las edificaciones previstas, la necesidad de reservar terrenos para garantizar el acceso al mar y el deber de disponer los espacios libres y zonas verdes en la posición más próxima posible a la línea de costa.

La inclusión de los suelos dentro de la categoría de suelo no urbanizable costero, tanto en el caso del PDUSC-1 como del PDUSC-2, conlleva su adscripción a las denominadas Unidades Territoriales de Regulación del Suelo Costero (UTR), a cada una de las cuales se confiere unas determinadas posibilidades de uso. Así, el PDUSC elabora para cada uno de los 237 ámbitos identificados y delimitados como UTR una completa ficha descriptiva y les confiere las posibilidades de uso siguientes:

a) Unidades Territoriales de Regulación del Suelo Costero 1 (UTR-C1). Se agrupan en esta subcategoría los suelos caracterizados por su valor intrínseco o por su capacidad de conexión entre los ámbitos propiamente costeros y el interior. En ellos se admiten sólo usos directamente relacionados con la naturaleza rústica de los terrenos y se mantiene un tratamiento notablemente restrictivo respecto cualquier otra utilización.

b) Unidades Territoriales de Regulación del Suelo Costero 2 (UTR-C2). Contienen suelos que, sin gozar de los valores de los anteriores, se caracterizan por su posición próxima a la ribera del mar, dentro de la franja de los $500 \mathrm{~m}$ desde la línea de costa. En este caso, el Plan, manteniendo su carácter rústico, admite otro tipo de usos, como equipamientos de interés público que deban emplazarse en el medio rural o instalaciones de camping.

c) Unidades Territoriales de Regulación del Suelo Costero 3 (UTR-C3). Son suelos que tienen idénticas condiciones que la subcategoría anterior, pero se caracterizan por su posición fuera de la franja de los $500 \mathrm{~m}$. Se les aplica la regulación de usos que la legislación urbanística confiere al suelo no urbanizable ordinario.

d) Unidades Territoriales de Regulación del Suelo Costero PEIN (UTR-CPEIN). Se incluyen en esta subcategoría los suelos incluidos en los ámbitos PEIN radicados en los primeros $500 \mathrm{~m}$ de la línea de costa.

\footnotetext{
${ }^{16}$ Sobre los objetivos y metodología del PDUSC-2 véase Joan Llort, "El segon Pla director urbanístic del sistema costaner: una intervenció en sòls urbanitzables delimitats sense pla parcial aprovat", en O. Nel·lo y J. Llort.

Pla Director urbanístic... cit (pp. 13-16). Las normas, las fichas descritivas y los planos normativos de este instrumento pueden encontrarse en el mismo volumen.
} 
Se les aplica el mismo régimen de usos que en las UTR-C1 a excepción de en aquellos casos en los que la normativa propia de los espacios PEIN implique un nivel de protección más alto.

e) Unidades Territoriales de Regulación del Suelo Costero Especiales (UTR-CE). Finalmente, algunas pocas áreas de suelo no urbanizable o suelo urbanizable no delimitado han sido clasificados dentro de esta categoría y dejadas a disposición del planeamiento municipal por si éste estima conveniente cambiar su régimen e incorporarlos al proceso urbanizador, en general como suelo de equipamientos o como zona verde.

\section{Magnitudes urbanísticas básicas}

Descrito el ámbito, los objetivos, la metodología y los instrumentos del PDUSC, conviene ahora detenerse en las magnitudes urbanísticas básicas. Así, tal como puede verse en la tabla 4 , los suelos protegidos por el PDUSC, bajo las clasificaciones de C1, C2, C3 y CPEIN suponen un total de 23551 $\mathrm{Ha}$, a las que cabría sumar las 2202 Ha de suelo no urbanizable existentes en los 1000 primeros metros de tierra a partir de la ribera interior del mar. Se trata de una superficie muy considerable, que supera los $230 \mathrm{~km}^{2}$ y se extiende sobre territorios equivalentes a dos veces y media el término municipal de Barcelona. Resulta interesante constatar que, si se excluye del cálculo el área urbana central de la metrópolis barcelonesa (es decir la costa de la comarca del Barcelonés), el suelo preservado supera con creces los suelos que ya son urbanos o disponen de planeamiento derivado definitivamente aprobado en el resto de la costa (U, UD* y UND*), los cuales, como puede verse suman una superfície de $19910 \mathrm{Ha}$.

Sin embargo, frente a quienes pudieran pensar que el plan supone una congelación absoluta del desarrollo urbano en el litoral catalán se debe constatar que el suelo urbanizable existente en los primeros 1000 metros de costa, UD y UND, que sin disponer todavía de planeamiento derivado aprobado podrá completar el ciclo urbanizador es de $4551 \mathrm{Ha}$. Si a esta superficie se añadiera todo el suelo considerado como especial, CE, el territorio que todavía resultaría urbanizable dentro de la franja de $1000 \mathrm{~m}$. sería de $5621 \mathrm{Ha}$, lo cual supone un potencial urbanístico en absoluto desdeñable ${ }^{17}$.

Tabla 4

Clasificación del suelo en el ámbito de aplicación del PDUSC

\begin{tabular}{|c|c|c|c|c|c|c|c|c|}
\hline Ámbito funcional ampliado $1.000 \mathrm{~m}$ & Comarca & $\mathrm{U}+\mathrm{UD}^{*}+\mathrm{UND}^{*}$ & $\mathrm{C} 1+\mathrm{C} 2+\mathrm{C} 3+\mathrm{CPEIN}$ & $\mathrm{NU}$ & $\mathrm{CE}$ & UD + UND & $\mathrm{UD}+\mathrm{UND}+\mathrm{CE}$ & VIVIENDAS \\
\hline \multirow{3}{*}{ Comarcas de Girona } & Alt Empordà & $2.098,04$ & $5.547,69$ & - & 98,63 & 519,92 & 618,55 & 15.464 \\
\hline & Baix Empordà & $2.728,81$ & $3.089,62$ & 148,99 & 41,39 & 342,35 & 383,74 & 9.594 \\
\hline & La Selva & $1.551,66$ & 883,89 & 7,42 & 21,86 & 288,51 & 310,37 & 7.759 \\
\hline \multirow{3}{*}{ Ámbito metropolitano de Barcelona } & Maresme & $3.421,43$ & $2.553,04$ & 447,34 & 210,47 & 350,80 & 561,05 & 14.026 \\
\hline & Barcelonès & 976,80 & 46,91 & - & - & - & - & \\
\hline & Baix Llobregat & 661,82 & 445,07 & 353,94 & 182,67 & - & 182,67 & 4.567 \\
\hline \multirow[b]{4}{*}{ Campo de Tarragona } & Baix Penedès & $1.166,59$ & 166,94 & 43,16 & 17,31 & 130,25 & 147,56 & 3.689 \\
\hline & Tarragonès & $2.330,82$ & 661,92 & 155,30 & 85,44 & 890,38 & 975,82 & 24.396 \\
\hline & Baix Camp & $1.949,31$ & $1.348,16$ & 990,67 & 65,65 & 849,88 & 915,53 & 22.888 \\
\hline & & $5.446,72$ & $2.177,02$ & $1.189,13$ & 168,40 & $1.870,51$ & $2.038,91$ & 50.973 \\
\hline \multirow{2}{*}{ Tierras del Ebro } & Baix Ebre & 852,55 & $4.206,93$ & - & 175,56 & 407,92 & 583,38 & 14.585 \\
\hline & Montsià & 527,06 & $3.611,27$ & - & 76,46 & 259,04 & 335,50 & 8.388 \\
\hline
\end{tabular}

Fuente: Dirección General de Urbanismo.

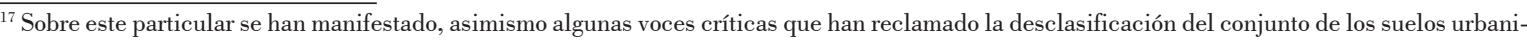
zables delimitados (con o sin plan parcial aprobado). Véase, por ejemplo, Greenpeace, Catalunya. Informe sobre la situació del litoral, Barcelona, Greenpeace, 2007 (28 pp.). Dejando aparte el hecho que algunos de los desarrollos previstos son necesarios para completar las tramas urbanas y la provisión de equipamientos, así como el efecto que la supresión taxativa del suelo urbanizable pudiera tener sobre los precios del suelo en los municipios litorales, se ha hecho notar (Josep M. Aguirre, L'ordenació del litoral..., cit., pp. 203-204) que esta opción podría plantear problemas de responsabilidad patrimonial para la Administración.
} 
$\mathrm{U}$ : Urbano

UD*: Urbanizable Delimitado con planeamiento derivado definitivamente aprobado

UND*: Urbanizable No Delimitado con planeamiento derivado definitivamente aprobado

UD: Urbanizable Delimitado sin planeamiento derivado definitivamente aprobado

UND: Urbanizable No Delimitado sin planeamiento derivado definitivamente aprobado

NU: No Urbanizable ordinario situado en los primeros $1000 \mathrm{~m}$.

C1, C2, C3, CPEIN: Suelos protegidos por el PDUSC

CE: Suelos incorporados al PDUSC susceptibles de albergar desarrollo urbanístico.

Por lo que a su distribución geográfica se refiere, los ámbitos costeros donde las protecciones del PDUSC tienen mayor incidencia territorial en términos de superficie son las comarcas gerundenses, seguidas de las Terres de l'Ebre. En cambio, la superficie protegida es lógicamente menor en los ámbitos más urbanizados del Camp de Tarragona y de la Región Metropolitana de Barcelona, en las que, como puede verse, se siguen concentrando los potenciales de crecimiento más altos.

De los datos expuestos se deducen diversas conclusiones. En primer lugar que, por su extensión y ambición el PDUSC ha venido a representar el ejercicio de planeamiento urbanístico supramunicipal más ambicioso llevado a cabo en Cataluña desde el Plan General Metropolitano de Barcelona de 1976. Se ha constatado asimismo que los suelos protegidos por el Plan representan una superficie muy respetable, capaz de dejar una impronta determinante en el desarrollo urbanístico del litoral catalán. Ahora bien, los suelos que no disponiendo todavía de planeamiento derivado definitivamente aprobado podrán seguir su desarrollo contienen todavía un potencial de crecimiento notable.

\section{La tramitación y gestión del Plan}

A criterio de sus impulsores, este carácter ponderado del Plan ha sido, seguramente, un elemento clave para que el proceso de tramitación, aproba- ción y aplicación del PDUSC se haya producido con un alto nivel de consenso y celeridad. Por otra parte, el Plan, partiendo de la noción de que, para pervivir, todo instrumento urbanístico requiere de mecanismos de adaptación y aplicación, establece, además del marco normativo, diversos instrumentos para su despliegue, financiación y gestión.

\section{La tramitación legal}

Desde el punto de vista jurídico, los objetivos y contenido de los planes directores urbanísticos son regulados por la legislación urbanística catalana (Texto Refundido de la Ley de Urbanismo de Cataluña, Decreto legislativo 1/2005). De acuerdo con la norma, los planes constan de la documentación siguiente: memoria, normativa, bases técnicas y económicas para su desarrollo, programación de las actuaciones necesarias, planos de información (en el caso del PDUSC, un plano de emplazamiento 1/500 000, 32 ortofotomapas 1/20 000, 32 planos de información del régimen urbanístico l/20 000), planos de ordenación (32 planos 1/20 000), estudio diagnóstico socio-económico del ámbito y fichas resumen del trabajo de campo para cada uno de los ámbitos incluidos en el plan.

Como se ha dicho, el PDUSC está compuesto formalmente de dos documentos, que conocieron procesos de tramitación y aprobación separados: el Plan Director Urbanístico del Sistema Costero de Cataluña (PDUSC-1) y el Plan Director Urbanístico de los ámbitos del sistema costero integrados por sectores de suelo urbanizable delimitado sin planeamiento parcial definitivamente aprobado (PDUSC-2).

El PDUSC-1 inició su tramitación el día 4 de febrero de $2004^{18}$, con la suspensión de trámites y licencias y la comunicación del documento de criterios y objetivos a los ayuntamientos. Después de los oportunos trámites de información pública e información institucional, el Plan quedó aprobado de manera definitiva poco más de un año después el 25 de mayo de $2005^{19}$. Del elevado grado de consenso con que contó el Plan desde su inicio da cuenta el hecho de que en el período de información pública se recogieran 452 alegaciones, a razón de

\footnotetext{
${ }^{18}$ Es decir, apenas cuarenta días después de la toma de posesión del Gobierno de la Generalitat presidido por Pasqual Maragall, en el cual el cargo de Consejero de Política Territorial y Obras Públicas era ostentado por Joaquim Nadal. La dirección del equipo redactor del PDUSC fue confiada a Oriol Nel-lo y Joan Llort, Secretario para la Planificación Territorial y Director General de Urbanismo, respectivamente.

${ }^{19}$ Diari Oficial de la Generalitat de Catalunya, 16 de junio 2005.
} 
menos de 1 alegación por kilómetro de costa o poco más de 6 alegaciones por municipio. Por su parte, el PDUSC-2 inició la parte más decisiva de su singladura el 28 de mayo de 2005, coincidiendo su aprobación inicial con la definitiva del PDUSC-1, y conoció la aprobación definitiva el 16 de diciembre de $2005^{20}$. Se presentaron en su tramitación 168 alegaciones.

La litigiosidad posterior a la aprobación de los planes ha sido también muy escasa. Frente al PDUSC-1 se presentaron 186 recursos mientras que para el PDUSC-2 fueron 92; y se elevaron a los tribunales 103 contenciosos administrativos (81 ante el PDUSC-1, y 22 ante el PDUSC-2 que estan resultando hasta la fecha de manera muy mayoritaria en sentencias favorables al plan). Con posterioridad a su aprobación, el Plan ha sido objeto de dos modificaciones: una para establecer la regulación de dos promontorios en el término de Castell-Platja d'Aro, aprobada el 17 de abril de 2007, y otra, más substancial, instada por cuatro ayuntamientos entorno al aeropuerto de Barcelona para ajustar las determinaciones del PDUSC a los límites del Plan director del Aeropuerto de Barcelona, y que fue definitivamente aprobada el mes de diciembre de 2008.

\section{La adaptación del planeamiento a las previsiones del PDUSC}

Las determinaciones del PDUSC son normativas y vinculantes para las administraciones y los particulares. Como se ha dicho, el Plan contiene un conjunto de normas de aplicación directa, en particular por lo que se refiere a la regulación de usos del suelo no urbanizable costero. Sin embargo otra parte de las disposiciones del PDUSC constituyen directrices para el planeamiento municipal, de modo que, para su efectividad, resulta esencial que éste se adapte, en lo que al régimen de suelo se refiere a las prescripciones del Plan Director.

Aún cuando los ayuntamientos no han emprendido, por lo general, modificaciones de su planeamiento con el objetivo específico de adaptarse al PDUSC, todo el planeamiento derivado y el planeamiento general aprobado con posterioridad a su entrada en vigor ha debido respetar escrupulosamente las determinaciones del Plan. En este sen- tido, resulta de particular significación la sujeción al PDUSC de los 12 Planes de Ordenación Urbana de municipios costeros aprobados desde la entrada en vigor del Plan Director (ver Tabla 5)

\section{Tabla 5}

Municipios costeros con aprobación de Plan de Ordenación Urbanística Municipal posterior al PDUSC

\begin{tabular}{|l|r|r|}
\hline Municipio & Población 2009 & Aprobación POUM \\
\hline Cambrils & 30956 & Febrero, 2005 \\
\hline Cunit & 11730 & Noviembre, 2006 \\
\hline Lloret de Mar & 37734 & Diciembre, 2005 \\
\hline Malgrat de Mar & 18261 & Octubre, 2005 \\
\hline Mont-Roig del Camp & 11131 & Noviembre, 2006 \\
\hline Palafrugell & 22109 & Octubre, 2006 \\
\hline Palamós & 17766 & Octubre, 2008 \\
\hline Premià de Dalt & 27545 & Mayo, 2007 \\
\hline Sant Feliu de Guíxols & 21726 & Noviembre, 2005 \\
\hline Santa Cristina d'Aro & 4713 & Julio, 2007 \\
\hline Sitges & 27070 & Septiembre, 2005 \\
\hline Tossa de Mar & 5845 & Diciembre, 2005 \\
\hline
\end{tabular}

Fuente: Dirección General de Urbanismo. Generalitat de Catalunya

Otro elemento que ha venido a consolidar el PDUSC ha sido la incorporación de sus previsiones en el planeamiento territorial elaborado y aprobado desde su entrada en vigor. Es esta una cuestión esencial, puesto que de no contar con el marco territorial adecuado, la efectividad de algunas de las propuestas del Plan - como la de conectar espacios abiertos del litoral y el interior - podría haberse visto menguada. Asimismo, de no haberse establecido de manera inmediatamente sucesiva a las limitaciones para la urbanización en la franja costera derivadas del PDUSC regulaciones para las localidades adyacentes, la presión urbanizadora podría haberse transmitido a estas últimas. Es por esto que, ya la misma Memoria del PDUSC, establece que el Plan se propone ser, a un tiempo, "medida inmediata de protección de uno de los ámbitos más sensibles y necesitados" y "medida complementaria del programa de planeamiento territorial".

Para conjurar estos riesgos, los planes territoriales elaborados en los últimos años disponen en todos los casos la protección de suelos vecinos a los ámbitos protegidos por el PDUSC para conectarlos con los ámbitos de interés natural situados en el interior. Por otra parte, los planes territoriales incluyen el "suelo no urbanizable costero" dentro 
de la categoría de "suelo de protección especial", de modo que este disponga no sólo de la protección del planeamiento urbanístico, sino también del territorial. Finalmente, los planes territoriales contienen las oportunas estrategias de desarrollo de los núcleos situados en la segunda línea de costa para evitar que aparezcan allí las tramas urbanas aisladas de segunda residencia o los crecimientos desproporcionados al tamaño de las localidades que no podrán tener lugar ahora en el espacio litoral. Así se ha hecho en el caso del Plan Director Urbanístico del Empordà (aprobado definitivamente en octubre 2006, ver Figura 11), y en los Planes Territoriales Parciales del Camp de Tarragona, de la Región Metropolitana de Barcelona y de les Terres de l'Ebre (en tramitación).

\section{Figura 11}

Plan Director Territorial del Empordà: Suelos de protección.

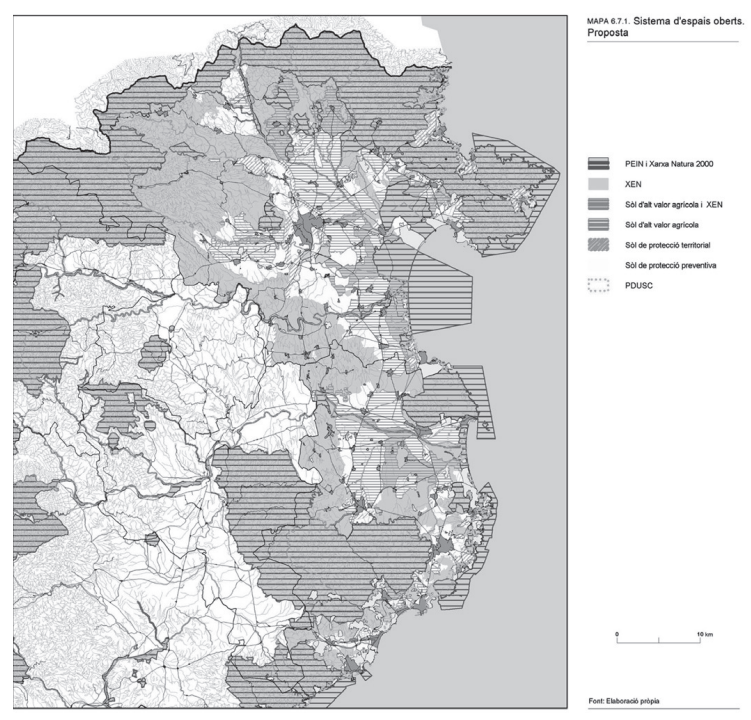

Fuente: Programa de Planificación Territorial, 2008. Generalitat de Catalunya

\section{La gestión del suelo no urbanizable}

Uno de los principales motivos de preocupación para los impulsores del Plan ha sido que éste proveyera no sólo vínculos urbanísticos sobre el régimen del suelo sino también instrumentos para la gestión del espacio que se propone mantener libre de urbanización. En efecto, en un contexto de dificultades, cuando no de regresión, de las actividades agrícolas y de presión por parte de los usos periurbanos, resulta esencial establecer mecanismos administrativos y financieros de gestión de los nuevos espacios protegidos. De lo contrario, los espacios tan arduamente preservados podrían venir a degradarse desde el punto de vista ambiental y paisajístico en un futuro más o menos cercano.

Así, las Bases Técnicas y Económicas para el desarrollo del PDUSC establecen la creación de un Fondo para la Gestión del Suelo No Urbanizable del Sistema Costero, dotado por la Generalitat con el objetivo de facilitar a los ayuntamientos y a las entidades de custodia del territorio recursos económicos en este campo. Pueden acudir al Fondo los entes locales o las entidades sin ánimo de lucro que en ámbito del suelo no urbanizable del sistema costero quieran llevar a cabo actuaciones en uno o varios de los siete campos siguientes:

a) La construcción y el mantenimiento de caminos de ronda

b) La construcción y el mantenimiento de accesos públicos para peatones o medios no motorizados a la zona de dominio público marítimo-terrestre

c) Adquisiciones destinadas a incrementar el patrimonio público de suelo no urbanizable en el ámbito costero (siempre que formen parte de actuaciones paisajísticas).

d) La reconstrucción de terrazas, márgenes y otros elementos.

e) La mejora de la cubierta vegetal

f) El derribo de instalaciones o edificaciones obsoletas o ilegales.

g) La adaptación paisajística de accesos, instalaciones o edificaciones ${ }^{21}$.

La primera convocatoria de ayudas del Fondo se llevó a cabo el año 2004, antes incluso de la aprobación definitiva del PDUSC, y desde entonces se ha repetido cada año. Las primeras cinco convocatorias han estado limitadas, por razones administrativas, a los ayuntamientos, pero se prevé que en el futuro podrán recibir ayudas del fondo las entidades de

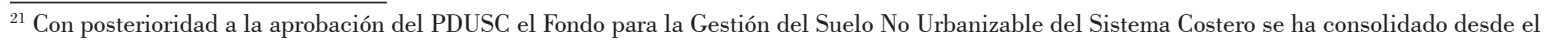
punto de vista normativo, al pasar a ser considerado una de las líneas específicas del Fondo para la protección, gestión y ordenación del paisaje, creado por la Ley 8/2005, de 8 de junio, de protección, gestión y ordenación del paisaje (art. 16-20). El Reglamento que desarrolla la Ley establece, en su artículo 27, el Fondo para la gestión del suelo costero como una de las líneas específicas de financiación previstas por la Ley (siendo otras líneas específicas el Fondo para la mejora de las colonias industriales y el Fondo para la creación de vías arboladas).
} 
custodia del territorio sin ánimo de lucro. En el caso de los consistorios se ha establecido que la ayuda procedente del Fondo puede representar hasta el $50 \%$ de los recursos necesarios para desarrollar la actuación, mientras que en el caso de las entidades sin ánimo de lucro la financiación podrá alcanzar el $10 \%$.

En las cinco convocatorias ya otorgadas (2004-2008), el Fondo para la gestión del suelo no urbanizable del sistema costero ha permitido comprometer inversiones en los suelos protegidos por el PDUSC por valor de 15,9 millones de $€$, de los cuales 4,5 han sido aportados por la Generalitat y 11,4 por los ayuntamientos, tal como puede verse en la Tabla 6 . Así, a lo largo de este período han accedido a las ayudas 31 de los 75 municipios con suelo en el ámbito del PDUSC, los cuales, como refleja la Tabla 7 , han invertido los recursos en construcción de caminos de ronda $(15,2 \%)$, naturalización $(9,6 \%)$, adquisición de terrenos y fincas $(13,4 \%)$, accesos al dominio público y paseos marítimos y fluviales $(61,9 \%)^{22}$. Algunas de las realizaciones ejecutadas con recursos procedentes del Fondo pueden verse en las figuras 12,13 y 14 .

Tabla 6

Inversión para la gestión del suelo no urbanizable del sistema costero

\begin{tabular}{|c|c|c|c|}
\hline Año & Subvención Fondo & $\begin{array}{c}\text { Inversión } \\
\text { Ayuntamientos }\end{array}$ & Inversión total \\
\hline $\mathbf{2 0 0 4}$ & 790523 & 961324 & 1751847 \\
\hline $\mathbf{2 0 0 5}$ & 1186312 & 3390251 & 4576563 \\
\hline $\mathbf{2 0 0 6}$ & 1079799 & 2419437 & 3499236 \\
\hline $\mathbf{2 0 0 7}$ & 828215 & 1207647 & 2035862 \\
\hline $\mathbf{2 0 0 8}$ & 640377 & 3433645 & 4074022 \\
\hline Total & $\mathbf{4 5 2 5} \mathbf{2 2 6}$ & $\mathbf{1 1} \mathbf{4 1 2} \mathbf{3 0 4}$ & $\mathbf{1 5} \mathbf{9 3 7 5 3 0}$ \\
\hline
\end{tabular}

Fuente: Dirección General de Arquitectura y Paisaje. Generalita de Catalunya

\section{Tabla 7}

Resumen de las tipologías de actuaciones en el suelo no urbanizable del sistema costero (2004-2008)
De esta forma, aún cuando los recursos disponibles son limitados y muchas de las actuaciones previstas se encuentran todavía en fase de ejecución, el Fondo para la gestión del sistema costero se ha ido asentando como un interesante complemento financiero para la gestión del PDUSC.

\section{Figura 12}

Proyecto de construcción de un puente-pasarela para viandantes sobre el río Fluvià en San Pere

Pescador

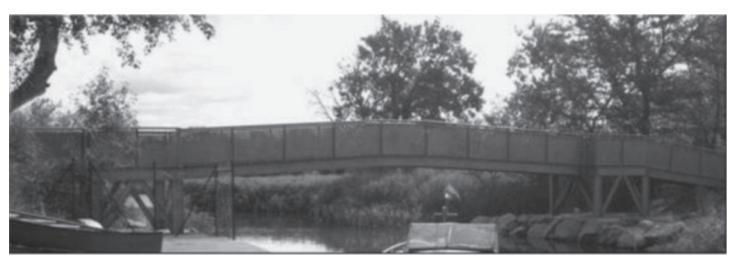

Fotografía: Isabella Longo, 2007

\section{Figura 13}

Adquisición de una finca por el acceso y el aparcamiento a la Playa de l'Estany Tort, en Ametlla de mar

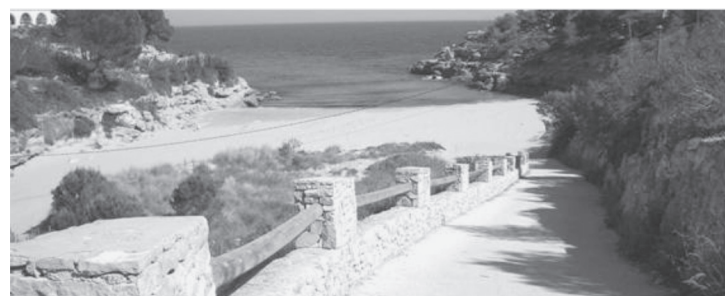

Fotografía: Isabella Longo, 2007

Figura 14

Camino de ronda entre playa Garbet y Portbou

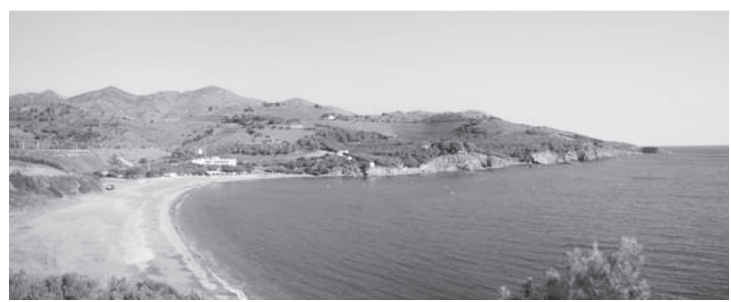

Fotografía: Isabella Longo, 2007

\begin{tabular}{|l|r|r|r|r|r|}
\hline $\begin{array}{r}\text { Tipolgías } \\
\text { de intervención }\end{array}$ & Accesos y Paseos & Caminos de Ronda & Naturalización & $\begin{array}{r}\text { Adquisición de fincas } \\
\text { y suelo }\end{array}$ & Total \\
\hline Período 2004-2008 & 9857810 & 2416830 & 1522148 & 2140742 & $\mathbf{1 5 9 3 7 5 3 0}$ \\
$\%$ & 61,9 & 15,2 & 9,6 & 13,4 & $\mathbf{1 0 0 , 0}$ \\
\hline
\end{tabular}

Fuente: Dirección General de Arquitectura y Paisaje. Generalitat de Catalunya

\footnotetext{
${ }^{22}$ Sobre la utilización del Fondo, véase el interesante trabajo de Isabella Longo, El planeamiento de la costa...cit. (pp. 41- 74).
} 


\section{Conclusiones: espacios litorales, proceso de urbanización y planeamiento supramunicipal}

De la experiencia de elaboración, tramitación, aprobación y gestión del PDUSC, con sus aciertos y sus limitaciones, pueden derivarse, a nuestro entender, algunas reflexiones de interés para el debate disciplinar y ciudadano acerca de los instrumentos de planeamiento urbanístico supramunicipal y, más concretamente, sobre su capacidad de ordenar el proceso de urbanización en los espacios litorales. Estas conclusiones, necesariamente provisionales dado el carácter todavía reciente del episodio, pueden agruparse en los diez postulados siguientes.

a) Las dinámicas de integración y transformación territorial contemporáneas imponen, de manera perentoria, la necesidad de innovar los instrumentos de ordenación del territorio en pos del bienestar de las generaciones actuales y venideras. Sólo a través de estos renovados instrumentos, legales y de planeamiento, la colectividad, podrá orientar y, cuando sea necesario, corregir, las tendencias espontáneas generadas por el mercado y por el juego de intereses particulares. Ello resulta particularmente patente en las áreas sometidas a una intensa presión urbanizadora, como los espacios costeros.

b) En la fase actual del proceso de urbanización estos instrumentos deben impulsar un modelo de ordenación del territorio que, frente a los riesgos emanados de la dispersión de la urbanización, la especialización funcional de los lugares y la segregación de los grupos sociales, propugne la existencia de una red urbana articulada y potente. Una red integrada por pueblos y ciudades cada uno de los cuales se caracterice por la búsqueda de la compacidad física, la complejidad de usos y la cohesión social. Por si mismo, este modelo de ordenación no es, ciertamente, un instrumento suficiente para garantizar la sostenibilidad ambiental, la eficiencia funcional y la equidad social -las cuales requieren de la existencia de muchas otras políticas económicas y sociales. Pero constituye un factor absolutamente necesario para el avance hacia estos objetivos. c) Entre los instrumentos normativos a disposición de la colectividad para impulsar este modelo de ordenación, el planeamiento urbanístico está llamado a desempeñar un papel crucial, como forma de concretar sobre ámbitos precisos la defensa de los valores más arriba enunciados. Ahora bien, en un territorio crecientemente integrado e interdependiente, el planeamiento municipal no puede, por si solo, encauzar de manera eficiente las dinámicas de transformación en curso. El ejemplo de las áreas costeras al que nos hemos referido es una muestra palmaria de la importancia y los límites del planeamiento urbanístico municipal a la hora de afrontar dinámicas y retos de alcance general.

d) Por ello resulta esencial disponer de instrumentos de ordenación de carácter supramunicipal, cuya necesidad se deriva directamente de la creciente integración del territorio, así como de su uso extensivo por parte de los ciudadanos y los agentes económicos. El planeamiento supramunicipal debe ser, en primer lugar, de carácter territorial, para fijar las estrategias generales relativas a los sistemas de espacios abiertos, asentamientos e infraestructuras para el conjunto del territorio. Pero al mismo tiempo son necesarios instrumentos de ordenación supramunicipal de carácter urbanístico, para dotar de directrices concretas el planeamiento municipal de determinadas áreas. Entre estos destacan, por su utilidad y versatilidad, los planes directores urbanísticos.

e) A la hora de delimitar los ámbitos de los planes directores urbanísticos deberá primar la ambición de abarcar, por encima de consideraciones administrativas, ámbitos territoriales significativos, con problemáticas que requieran un tratamiento de conjunto (como por ejemplo, las áreas costeras). Son, pues, los retos y las soluciones las que han de guiar de forma prioritaria las delimitaciones del planeamiento y no los límites administrativos. Por otra parte, no resulta necesario cubrir la totalidad del territorio con los mismos instrumentos de planeamiento urbanístico: un territorio ca- 
racterizado por la diversidad casa mal con planteamientos y geometrías homogéneas y totalizadoras.

f) La diversidad territorial impone también una cierta diversidad temática. Bien es verdad que los planes directores deben partir de consideraciones de conjunto y de la voluntad de impulsar una ordenación territorial comprehensiva. Ahora bien, en no pocas ocasiones la experiencia muestra la importancia de conferirles un carácter muy intencionado y finalista, destinado a asegurar algunas operaciones clave para la articulación de su ámbito: la preservación del suelo no urbanizable, la recuperación patrimonial o urbana, la disposición de sectores para actividad económica, el adecuado encaje de una intervención infraestructural. Tan importante como definir la temática que los planes contienen, es establecer, de manera taxativa, los aspectos que deben quedar fuera de su alcance. Sólo de esta forma los planes directores urbanísticos encontrarán su función entre los planteamientos estratégicos del planeamiento territorial y la concreción extrema del planeamiento municipal.

g) Esta concepción innovadora de los instrumentos de ordenación debe comportar, asimismo, la renuncia a algunos de los viejos conceptos del planeamiento, como la necesidad de establecer una prelación temporal en la elaboración de los planes de diversas escalas. Se trata de la vieja idea de la "cascada de planeamiento", es decir el principio según el cual el planeamiento debería elaborarse de forma sucesiva desde las escalas más altas hasta las más concretas, presupuesto que no se compadece bien ni con el funcionamiento de la Administración ni con la necesidad de concertar determinaciones a diversos niveles de escala. Antes al contrario, como se ha visto en el caso del planeamiento costero, resulta muy útil e interesante elaborar de manera coincidente en el tiempo diversos instrumentos que consideran un mismo territorio desde la escala del planeamiento territorial, director o urbanístico. Así, los planes concebidos a diversos niveles de escala interactúan y se condicionan mutuamente. h) Un plan director debe ser ante todo el instrumento de gestión de un proceso. Así, otra noción que decae es la necesidad de establecer una "imagen objetivo final", como propugnaba el planeamiento a la vieja usanza: la adopción de una imagen fija hacia la que tender, que debería ser alcanzada, en teoría, al final del período de vigencia del plan. Frente a estos presupuestos, el planeamiento supramunicipal adaptado a las necesidades de hoy debe más bien establecer un conjunto de reglas y directrices capaces de orientar el uso y gestión del territorio durante su período de vigencia. Reglas y directrices capaces de hacer prevalecer y exaltar los valores sociales, ambientales y económicos que se persiguen, aún cuando la ordenación final del territorio no sea rígidamente definida en su integridad por el Plan en el momento de su aprobación, sino el resultado de la interacción a lo largo del tiempo de una gran variedad de actores.

i) En este sentido, el plan director debe contener no sólo las normas y los planos capaces de establecer vínculos urbanísticos en el uso del suelo, sino que ha de proveer asimismo instrumentos para su desarrollo y aplicación. Éstos deben ser, en primer lugar, de carácter administrativo, como la previsión de los planes municipales que desarrollarán y concretarán las directrices del planeamiento supramunicipal. Pero el plan director ha de impulsar asimismo mecanismos prácticos y contingentes para la gestión y la financiación, en las que habrán de intervenir el conjunto de las administraciones concernidas. En las áreas costeras, para seguir con el caso analizado en este artículo, no es suficiente, como se ha visto, establecer el vínculo urbanístico de la protección del suelo, sino que, para evitar la degradación de los espacios litorales, resulta decisivo dotarse de herramientas de gestión paisajística, patrimonial e infraestructural como el Fondo para la Gestión del suelo no urbanizable del sistema costero al que se ha hecho referencia.

j) Finalmente, los planes territoriales y los planes directores deben ser fruto de procesos de concertación, democracia deliberativa 
y buen gobierno. Así, estos planes requieren, en primer lugar, del acuerdo entre los gobiernos de las comunidades autónomas y los ayuntamientos concernidos. Y han de ser, también, lugar de encuentro entre la administración pública y los agentes económicos y sociales de cada uno de los ámbitos de planeamiento. Para ello hará falta, ciertamente, extremar la voluntad de diálogo e implicación por parte de todas las partes ya desde el mismo proceso de elaboración del plan y, por supuesto, a lo largo de su tramitación. Y se requerirá sobre todo que todas las administraciones públicas implicadas tengan la voluntad de cumplir y hacer cumplir el plan.

Hasta aquí las principales enseñanzas que se derivan de la experiencia del Plan Director Urbanístico del Sistema Costero catalán y de otros planes supramunicipales elaborados en los últimos años. Ahora bien, puede añadirse que, junto a los elementos jurídicos, políticos, administrativos y técnicos que se han expuesto, otro factor ha resultado decisivo a la hora de determinar el mayor o menor éxito de estos ejercicios de planeamiento: la cultura ciudadana sobre la ordenación del territorio. Si un instrumento del alcance del PDUSC, para citar por última vez el ejemplo, se ha podido venir a aprobar y aplicar con un nivel de acuerdo tan alto y de litigiosidad tan escasa, es porqué existía un elevado consenso social respecto a los objetivos y valores que el plan propugnaba. Este consenso nunca podrá ser absoluto, porque la diversidad de intereses es consubstancial a toda sociedad. Pero no resulta aventurado afirmar que el futuro de la ordenación del territorio depende, en muy buena medida, de la forma como se extienda y prevalezca una nueva cultura del territorio basada en los valores del respeto ambiental, la racionalidad funcional y la cohesión social. 


\section{Bibliografía}

Aguirre, J. M. (2007): L'ordenació del litoral catalá: els plans directors urbanístics del sistema costaner, Barcelona, Atelier, (p. 217).

Diversos Autores, (2005): Debat Costa Brava, Congrés: Un futur sostenible. Colegio de Arquitectos de Cataluña, Demarcación de Girona. (p. 402).

Diversos Autores, (2007): Catalunya. Informe sobre la situació del litoral, Barcelona, Greenpeace, (p. 28).

Diversos autores, Anuari Territorial de Catalunya, Barcelona, Societat Catalana d'Ordenació del Territori, 2004-2006.

Esteban, J. (2009): "El Planejament Territorial a Catalunya, avui", en Tria. Rivista internazionale di cultura urbanistica, 3, junio 2009 (p. 153-167).

Folch, R. y Paris, A (dir.) (1999): Atles ambiental de la Mediterrània. L'estructura del territori $i$ del paisatge, Barcelona.

Institut Català de la Mediterrània - Institut Cartogràfic de Catalunya, (p. 220).

Llort, J. (2006): “El segon Pla director urbanístic del sistema costaner: una intervenció en sòls urbanitzables delimitats sense pla parcial aprovat", en Nel·lo, O. y Llort, J. (dir.), Pla Director Urbanístic del Sistema Costaner, Barcelona, Generalitat de Catalunya, (pp. 13-16).

Longo, I. (2007): El planeamiento de la costa: el caso catalán, Venecia, Istituto Universitario di Architettura di Venezia, (p. 89) (tesis de licenciatura)

Martí, C. (2001): La transformació del paisatge litoral del centre de la Costa Brava en els darrers cinquanta anys. Palamós, Calonge i Castell-Platja d'Aro, Gerona, Unidad de Geografía de la Universitat de Girona. (Memoria de investigación).

Nel·lo, O. (2001): "Las áreas metropolitanas", en Gil Olcina, A y Gómez Mendoza, J. (coord.) Geografía de España. Barcelona, Ed. Ariel. (p. 275-289)

Nel·lo, O. (2002): Cataluña, ciudad de ciudades Lleida, Milenio, (p. 160).

Nel·lo, O. (2004): "¿Cambio de siglo, cambio de ciclo? Las grandes ciudades españolas en el umbral del siglo XxI", en Ciudad y territorio. Estudios territoriales, xxxVI, 141-142, otoño-invierno (pp. 523-542).
Nel·lo, O. (2005): "La Nuova Politica Territoriale della Catalogna" en Archivio di Studi Urbani e Regionali, 83, (pp. 39-70). Nel·lo, O. (2006): "El Pla Director Urbanístic del Sistema Costaner: una aposta de futur", en Nel·lo, O. y Llort, J. (dir.) Pla Director Urbanístic del Sistema Costaner, Barcelona, Generalitat de Catalunya, (pp. 9-12).

Nel·lo, O. (2006): "Els plans directors urbanístics de Catalunya. Una nova generació de plans", en Espais, 52, Otoño 2006. Departament de Política Territorial o Obres Públiques (p. 3-11).

Nel·lo, O. y Llort, J. (dir.), (2006): Pla Director Urbanístic del Sistema Costaner, Barcelona, Generalitat de Catalunya, (p. 383).

$\mathrm{Nel} \cdot l$, O. (2009): “La renovación del planeamiento urbanístico suparmunicipal. El Plan Director Urbanístico del Sistema Costero de Cataluña" en Galiana, L. y Vinuesa, J. Teoría y práctica para una ordenación racional del territorio, (en prensa).

Nogué, J. (2005): "La transformació del territori i del paisatge de la Costa Brava (1956-2003). Situació actual i propostes d'actuació" en III Debat Costa Brava, Colegio de Arquitectos de Cataluña, Demarcación de Girona, (pp. 88-121).

Nuell, H. (2001): Evolució dels usos del sòl a la Costa Brava 1957-1993 Gerona, Unidad de Geografía de la Universitat de Girona. (Memoria de investigación).

Oliveras, J. y Gonzalez, F. (2003): Ordenació territorial i sostenibilitat al Camp de Tarragona, Tarragona, Fundació Recasens i Mercadé (p. 225).

Riera, P. y Haas, C. (2006): "Los planes directores del litoral de Cataluña”, en Romero, J. y Farinós, J., Gobernanza territorial en España, València, Universitat de València, (pp. 47-60).

Secretaria per a la Planificació Territorial, (2006): Planejament territorial. Criteris. Departament de Política Territorial i Obres Públiques. (p. 28)

Vicente, J. y Gutierrez, O. (2004): “La construcció d'habitatge a la provincia de Girona" en La Punxa. Col-legi d'Aparelladors i Arquitectes tècnics de Girona, 36. (pp. 6-54). 